\title{
EFFECT OF ROCURONIUM ON THE HEART RATE AND ARTERIAL BLOOD PRESSURE DURING COMBINED GENERAL ANAESTHESIA
}

\author{
Urszula Kosciuczuk ${ }^{1} \odot$, Paulina Gluszynska ${ }^{2} \odot$, Inna Diemieszczyk ${ }^{2} \odot$, Aleksander Lukaszewicz ${ }^{2}$, \\ Krzysztof Bauer ${ }^{3}$, Maciej Kokoszko ${ }^{4}$, Lukasz Szarpak ${ }^{5} \odot$, Jerzy Robert Ladny ${ }^{3}$, Hady Razak Hady ${ }^{2} \odot$ \\ ${ }^{1}$ Department of Anaesthesiology and Intensive Therapy, Medical University of Bialystok, Poland \\ ${ }_{2}^{2} 1^{\text {st }}$ Department of General Surgery and Endocrine Surgery, Medical University of Bialystok, Poland \\ ${ }^{3}$ Department of Emergency Medicine and Disaster, Medical University of Bialystok, Poland \\ ${ }^{4}$ Cancer Treatment Centre in Bialystok, Bialystok, Poland \\ ${ }^{5}$ Institute of Outcomes Research, Maria Sklodowska-Curie Medical Academy, Warsaw, Poland
}

\begin{abstract}
INTRODUCTION: Additional mechanisms of neuromuscular blocking agents action create the haemodynamic condition during general anaesthesia. The aim was to investigate the effect of rocuronium on haemodynamic parameters during combined general anaesthesia.
\end{abstract}

MATERIAL AND METHODS: The study was conducted in two groups: Group I underwent combined anaesthesia with rocuronium and Group II - combined anaesthesia without any muscle relaxants. Haemodynamic parameters: heart rate, systolic, diastolic and mean arterial blood pressure were recorded before anaesthesia, at the end of rocuronium infusion, and after recovery from anaesthesia.

RESULTS: In both groups, the values of the median heart rate, systolic, diastolic and mean arterial blood pressure recorded before and after anaesthesia were similar and did not differ significantly.

In Group I, significant reduction in heart rate in the end of rocuronium infusion [74 (61-103)], $(p=0.01)$ and after recovery from anesthesia [71 (53-100)], $(p=0.03)$, compared to the value before anesthesia [81 (56-104)], were demonstrated. Additionally, significant reduction in systolic [130 (96-169); 114 (92-144)], $(p=0.04)$, diastolic [80 (54-109); 73 (47-99)], $(p=0.01)$, and mean [95 (72-106); 85 (68-109)], $(p=0.02)$ arterial blood pressure in the end of rocuronium infusion were noticed. The values of systolic, diastolic and mean blood pressure after recovery from anaesthesia significantly increased in relation to the values observed in the end of the rocuronium infusion [129 (96-181)], $(p=0.01)$; 78 (47-107)], $(p=0.03)$; [93 (63-107)], $(p=0.03)$.

CONCLUSIONS: The vagolytic effect was not observed during general anaesthesia with rocuronium. The changes in heart rate and blood pressure were associated with the rocuronium infusion and were normalized after recovery from anaesthesia.

KEY WORDS: anaesthesiology, haemodynamic state, neuromuscular blocking agents

Disaster Emerg Med J 2021; 6(3): 104-111 


\section{INTRODUCTION}

Neuromuscular blocking agents, in addition to anaesthetics and opioid analgesics, are the main groups of pharmacological substances used for general anaesthesia. The main site of its action is the neuromuscular junction (motor plate), which connects the motor nerve fibre with the muscle fibres. Conduction of the nerve impulse in motor nerve fibres causes the release of acetylcholine $(\mathrm{ACH})$ into the synaptic space, which then binds with specific cholinergic receptors in the area of postsynaptic elements. In addition to the cholinergic receptors of the neuromuscular junction, ACH is a neurotransmitter for receptors located in the autonomic ganglia and the post-ganglionic endings of parasympathetic fibres [1-4].

Neuromuscular blocking agents have many other effects resulting from the significant role and diffusion of acetylcholine receptors. Circulatory symptoms associated with the use of depolarizing muscle relaxants result from an agonistic effect on the muscarinic receptors of the autonomic system and the heart sinus node and occur in the form of sinus bradycardia, nodal rhythms and ventricular arrhythmias. The effect of non-depolarizing muscle relaxants on the cardiovascular system is related to the antagonistic effect on the muscarinic receptors of the vagus nerve in the heart (vagolytic effect), activation of post-ganglionic adrenergic fibres, the release of catecholamines and inhibition of their uptake by adrenergic nerve endings [5-8].

Haemodynamic monitoring is important in all stages of general anaesthesia. The range of monitored parameters and the methods used depend on the general condition of the patient, surgical procedure, as well as an anaesthetic management. An analysis of the continuous electrocardiographic record, analysis of the rhythm and heart rate, invasive or non-invasive blood pressure measurements — systolic, diastolic, mean values, indirect and direct parameters recorded of Swann-Ganz catheter are used [9-12].

Rocuronium is a non-depolarizing neuromuscular blocking agent with a steroid structure that meets the requirements of modern anaesthesiology. The favourable pharmacokinetic profile makes it widely used in general anaesthesia, especially in specific categories such as paediatric anaesthesia, elderly patients, pregnancy in one-day anaesthesia, bariatric anaesthesia, and also in transplantation procedures [14-21].
Many publications have presented the results of studies on the effect of rocuronium used in the intubation dose on the haemodynamic status during induction of anaesthesia and tracheal intubation, in both groups of patients: undergoing cardiac surgery, as well as and non-cardiac surgery. Another important aspect is the correlation between the haemodynamic state and the rocuronium dose. This was because the rocuronium administration in the dose of $0.6 \mathrm{mg} / \mathrm{kg}$ causes the occurrence of intubation conditions after about 90 seconds, and the increase of the dose to $1.2 \mathrm{mg} / \mathrm{kg}$ makes the possibility of tracheal intubation after about 55 seconds. Therefore, there are questions about the dependence of haemodynamic changes and the rocuronium dose used, and the intubation conditions created. Currently, there are not many publications that present the influence of rocuronium on the haemodynamic parameters during other stages of general anaesthesia - especially in the maintenance phase of anaesthesia, and describing the haemodynamic status during continuous infusion of this neuromuscular blocking agent [13-18].

The study aimed to investigate the effects of rocuronium used in intubation dose and followed by infusion on haemodynamic parameters during combined general anaesthesia to non-cardiac surgery. The parameters of heart rate, mean, systolic and diastolic blood pressure were recorded during general anaesthesia and were used for the analysis.

\section{MATERIAL AND METHODS}

A prospective study was conducted at the Department of Anaesthesiology and Intensive Therapy, in cooperation with the Department of General and Endocrine Surgery at the Medical University of Bialystok, Poland. All patients were recruited by direct contact from a member of the medical staff. All patients were informed about the risk of surgical procedure and written informed consent was obtained from every participant before the surgery. Patients between 18 and 80 years of age in ASA (classification of the American Society of Anaesthesiologists) -1 (without additional disorders) or 2 (very well-controlled additional disorders without systemic complications) score, qualified to planned surgical operation under general anaesthesia were included. Patients in ASA 2 score with any cardiological disorders, ASA 3 (additional disorders with systemic complications) or 4 (a serious complication 
of additional disorders with a high risk of perioperative death) score qualified to elective surgery were excluded from the analysis.

The study was conducted in 126 patients divided into two groups due to the method of anaesthesia used. Group I - 66 patients who underwent combined general anaesthesia with the rocuronium to laparotomy. Group II - 60 patients who underwent combined general anaesthesia without the use of neuromuscular blocking agents to thyroidectomy. The algorithm of general anaesthesia is presented in Figure 1. In both groups, $500 \mathrm{ml}$ of Sterofundin was given intravenously before induction of anaesthesia, and volatile induction and maintenance of anaesthesia with sevoflurane (Sevorane, Abbvie) was performed. Analgesia was ensured through the administration of intravenous fractional doses of fentanyl at $2 \mu \mathrm{g} \mathrm{kg}-1$ (Fentanyl, Polfa) in the induction and maintenance phase of anaesthesia every 30 minutes.

During the induction of anaesthesia in Group I, after the adequate level of aesthetic sleep was assessed, neuromuscular blocking agent - rocuronium (Esmeron, Organon) in the dose of $0.6 \mathrm{mg} / \mathrm{kg}$ of body weight was administered and the monitoring of muscle relaxation with the use of Train-Of-Four (TOF) stimulation started. Tracheal intubation was performed when TOF 0 was assessed. When muscle relaxation returned to TOF 4 continuous infusion of rocuronium at a speed required to achieve TOF 0 was administered and stopped at the moment of surgical closing of the peritoneal cavity. Extubation was performed in patients with stable and spontaneous respiratory function with a TOF Ratio (TOFR) of 0.8-0.9.

A.
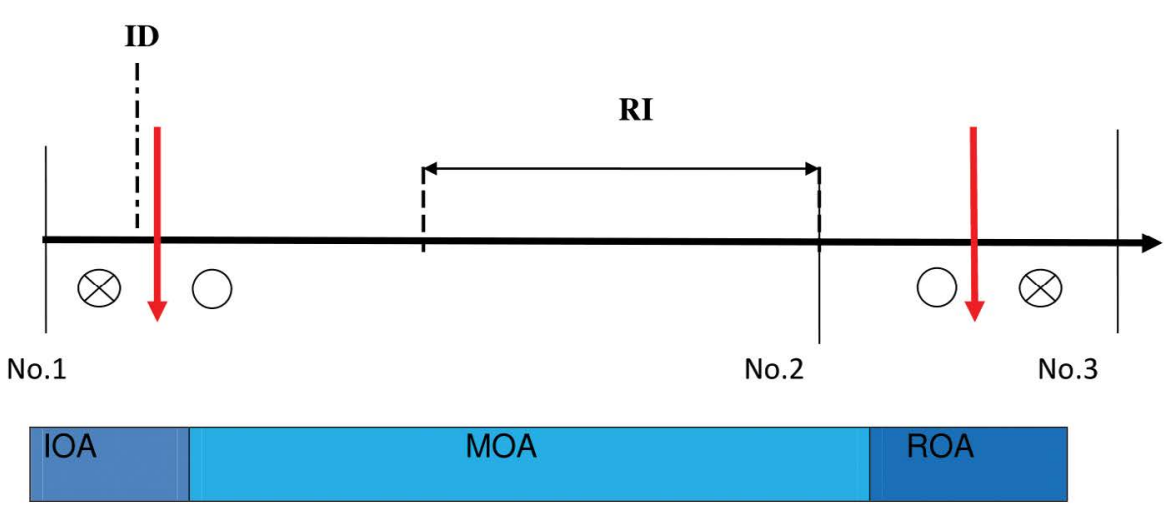

B.

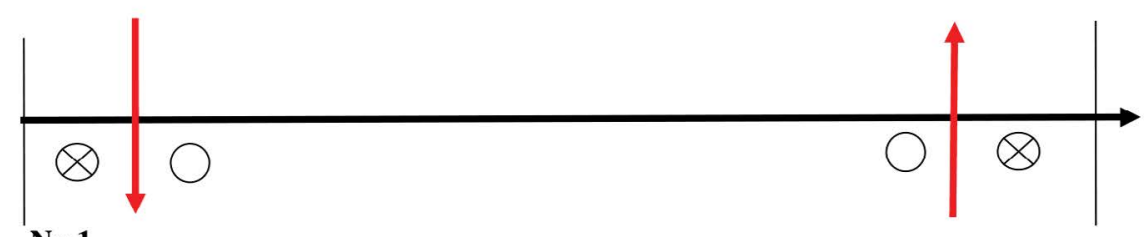

No.1

No.3

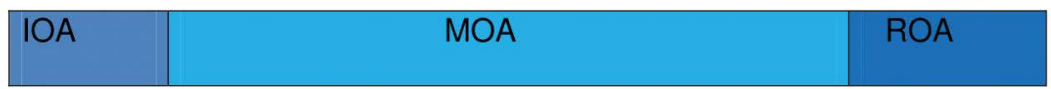

FIGURE 1. The scheme of perioperative period and stages of general anaesthesia

A. in Group I - general anaesthesia with rocuronium

B. in Group II - general anaesthesia without muscle relaxants

$\otimes$ start of anaesthesia, end of anaesthesia

o start of surgical procedure, end of surgical procedure

$\checkmark$ intubation extubation

No. 1, No. 2, No. 3 - point of haemodynamic parameters measurements

ID — intubating dose of rocuronium; IOA — induction of anaesthesia; MOA — maintenance of anaesthesia; RI — rocuronium infusion;

ROA — recovery of anaesthesia 
After the end of the surgical procedure, the administration of sevoflurane was stopped and access to fresh gasses was increased. After recovery from anaesthesia, the patient was transferred to the Post-Operative Room.

The values of haemodynamic parameters: heart rate, systolic blood pressure, diastolic blood pressure, mean pressure in specific points of anaesthesia were recorded. In Group I - the parameters were registered before anaesthesia (No.1), at the end of rocuronium infusion (No. 2) and immediately after recovery from anaesthesia (No. 3). In Group II - the parameters were recorded before (No. 1) and immediately after recovery from anaesthesia (No. 3). Additionally, haemodynamic parameters were recorded every 5 minutes in both groups. Non-invasive haemodynamic parameters were recorded using a Mindray cardiac monitor.

The study was approved by the Bioethical Committee of the Medical University of Bialystok, Poland, and registered at ClinicalTrials.gov (NCT).

\section{Statistical Analysis}

Statistical analysis was performed with the use of STATISTICA 12.0. The data were assessed for normality with the Shapiro-Wilk test. Since the data were not normally distributed, the values are quoted as median, minimum and maximum. Sample size (n) is indicated in the figure legends. For comparison of variables, the following tests were used where appropriate: Wilcoxon matched-pairs signed-rank test, and Mann-Whitney $U$ - test, Kruskal-Wallis test. A p value of 0.05 or less was taken to indicate a significant difference.

\section{RESULTS}

The study included 126 patients (median age 48 years old). In the total study group, ASA 1 and ASA 2 accounted for $53 \%$ and 47\%, respectively. The additional disorders in ASA 2 population were: arterial hypertension - 55 patients, type 2 diabetes mellitus -4 patients, chronic sinusitis -2 patients, chronic obstructive pulmonary disease -1 patient, asthma bronchialis - 3 patients. The Groups did not differ in anthropometric parameters, duration of surgery and anaesthesia (Tab. 1).

The median intubation dose of rocuronium was $55 \mathrm{mg}$ (min-max ranges 40-70 mg), median infusion dose was $40 \mathrm{mg}$ (min-max ranges 5-95 mg), the median time of infusion was 75 minutes (min-

Table 1. The characteristic parameters of the
Groups. Median ranges are presented
\begin{tabular}{|l|c|c|c|}
\hline & Group I & Group II & p value \\
\hline Number of patients (n) & 66 & 60 & \\
\hline Age (years) & 46 & 50 & N.S \\
\hline Weight (kg) & 74 & 77 & N.S \\
\hline Height (cm) & 168 & 165 & N.S \\
\hline ASA 1/ASA 2 (n) & $40 / 26$ & $27 / 33$ & N.S \\
\hline Duration of surgery (min.) & 95 & 86 & N.S \\
\hline Duration of anaesthesia (min.) & 110 & 123 & N.S \\
\hline
\end{tabular}

\begin{tabular}{|c|c|c|c|}
\hline \multicolumn{4}{|c|}{$\begin{array}{l}\text { Table 2. Haemodynamic parameters - heart rate, } \\
\text { systolic, diastolic, mean arterial blood pressure } \\
\text { before anaesthesia (No.1) and after recovery } \\
\text { from anaesthesia (No.2) in the study groups. The } \\
\text { median values, the range (the minimum and } \\
\text { maximum values) and statistical significance } \\
\text { between the studied groups are presented }\end{array}$} \\
\hline & Group I & Group II & $p$ value \\
\hline \multicolumn{4}{|c|}{ Heart Rate $(1 / \mathrm{min})}$. \\
\hline No.1 & $81(56-104)$ & $78(50-120)$ & N.S \\
\hline No.3 & $71(53-100)$ & $74(56-110)$ & N.S \\
\hline \multicolumn{4}{|c|}{ Systolic Blood Pressure $(\mathrm{mmHg})$} \\
\hline No.1 & $130(96-169)$ & $136(95-178)$ & N.S \\
\hline No.3 & $129(96-181)$ & $124(95-181)$ & N.S \\
\hline \multicolumn{4}{|c|}{ Diastolic Blood Pressure (mmHg) } \\
\hline No.1 & $80(54-109)$ & $80(54-109)$ & N.S \\
\hline No.3 & $78(47-107)$ & $68(54-107)$ & N.S \\
\hline \multicolumn{4}{|c|}{ Mean Blood Pressure (mmHg) } \\
\hline No.1 & $95(72-106)$ & $96(74-106)$ & N.S \\
\hline No.3 & $93(63-107)$ & $84(70-107)$ & N.S \\
\hline
\end{tabular}

max ranges 25-170 minutes), and median total dose of rocuronium was $90 \mathrm{mg}$ (min-max ranges 60-155 mg).

In both groups, the values of the median heart rate, systolic, diastolic and mean arterial blood pressure recorded before and after recovery from anaesthesia were similar and did not differ significantly (Tab. 2). The median values of haemodynamic parameters (heart rate, systolic, diastolic, mean blood pressure) during all periods of anaesthesia were similar in both groups: in Group I were 76, 120/75/88; in Group II - 74, 130/73/90, respectively.

In patients undergoing general anaesthesia with rocuronium, a significant reduction in heart rate after recovery from anaesthesia, compared to 
the value before anaesthesia, was demonstrated $(p=0.03)$. Additionally, in these patients, there was a significant reduction in heart rate, systolic, diastolic and mean arterial blood pressure at the end of rocuronium infusion compared to the values before anaesthesia, respectively by $8.7 \%(p=0.01), 12.4 \%$ $(p=0.04), 8.8 \%(p=0.01), 13.5 \%(p=0.02)$. There was also a significant increase in systolic, diastolic and mean blood pressure after recovery from anaesthesia in relation to the values observed at the end of the rocuronium infusion by $13.1 \%$ $(p=0.01), 6.8 \%(p=0.03), 11.9 \%(p=0.03)$ (Tab. 3).

Among patients undergoing anaesthesia without the use of muscle relaxants, no significant differences were found in the heart rate after recovery from anaesthesia, while in this group of patients a significant reduction in systolic, diastolic and mean blood pressure was found, by $8.9 \%(p=0,04), 15.0 \%$ $(p=0.01), 16.4 \%(p=0.01)$, respectively (Tab. 3$)$.

\section{DISCUSSION}

Neuromuscular blocking agents are important adjuvant to general anaesthesia. In the modern definition of general anaesthesia, it is not an obligatory pharmacological component. However, many authors emphasize that the use of this group of pharmacological substances is necessary during general anaesthesia for operations involving the opening of natural cavities. A typical action of muscle relaxants is to block the neuromuscular junction, inhibit the transmission of neural stimulation to myocytes, and cause skeletal muscle relaxation $[22,23]$.
Neuromuscular blocking agents are used in the induction phase of general anaesthesia to perform tracheal intubation, and in the maintenance phase of anaesthesia to create operating conditions and eliminate adverse muscle reflexes. The general practice is that agents with a depolarizing mechanism of action are only applicable in the induction phase of general anaesthesia, while agents with a non-depolarizing mechanism of action are used as repeated doses also during the maintenance phase of anaesthesia $[8,13]$.

In 1983, Booij and Crul announced a decalogue of ideal neuromuscular blocking agent, which was described as a non-depolarizing mechanism of action, quick onset of relaxation, short duration, fast recovery from effect, no accumulation in the system, no active metabolites, no adverse effects on the cardiovascular system and histamine release, reversal of effects by inhibitors of cholinesterase, and considerable potency $[2,13]$.

The cardiovascular effects of neuromuscular blocking agents have been investigated in many experimental and clinical studies. It has been described that the potency of the clinical cardiovascular effects is associated with chemical structure and in particular their similarity to $\mathrm{ACH}$. The authors suggested that if neuromuscular blocking agents are more similar in the structure to $\mathrm{ACH}$, the more strongly the circulatory symptoms are expressed. It was presented that the vagolytic effect is mainly connected with steroid derivatives, less with benzyl derivatives (atracurium and cis-atracurium) [5].

The most pronounced haemodynamic effects have been reported for pancuronium. It has been

\begin{tabular}{|c|c|c|c|c|}
\hline & & No. 1 & No. 2 & No. 3 \\
\hline \multirow[t]{2}{*}{ Heart Rate (1/min.) } & Group I & $81(56-104)$ & $74(61-103)^{\bullet}$ & $71(53-100)^{\bullet *}$ \\
\hline & Group II & $78(50-120)$ & - & $74(56-110)$ \\
\hline \multirow[t]{2}{*}{ Systolic Blood Pressure (mm Hg) } & Group I & $130(96-169)$ & $114(92-144)^{\bullet}$ & $129(96-181)^{*}$ \\
\hline & Group II & $136(95-178)$ & - & $124(95-181)^{\bullet}$ \\
\hline \multirow{2}{*}{$\begin{array}{l}\text { Diastolic Blood Pressure } \\
(\mathrm{mm} \mathrm{Hg})\end{array}$} & Group I & $80(54-109)$ & $73(47-99)^{\bullet}$ & $78(47-107)^{*}$ \\
\hline & Group II & $80(54-109)$ & - & $68(54-107)^{\bullet}$ \\
\hline \multirow[t]{2}{*}{ Mean Blood Pressure (mm Hg) } & Group I & $95(72-106)$ & $85(68-109)^{\bullet}$ & $93(63-107)^{*}$ \\
\hline & Group II & $96(74-106)$ & - & $84(70-107)^{\bullet}$ \\
\hline
\end{tabular}

$\cdot p<0.05$ compared with the value before anaesthesia; ${ }^{*} p<0.05$ compared with value at the end of rocuronium infusion 
shown that the phenomena of an increase in the heart rate are associated with the activation of muscarinic receptors. Muscarinic cardiac effects, described as increased cardiac output and pulmonary artery pressure, resulted from an inhibition of noradrenaline reuptake and stimulation of adrenergic endings of the autonomic system. Increased levels of adrenaline and noradrenaline have also been reported after tracheal intubation with pancuronium [5]. Gursoy et al. in an experimental study in atrium myocytes reported increases in heart rate for the use of pancuronium, but no clinical significance for the use of vecuronium, rocuronium and mivacurium. For all tested muscle relaxants, a dose-dependent effect was noted, but only for pancuronium, the effect was limited by the use of propranolol. The authors presented conclusions that the mechanism of action was related to beta-adrenergic receptors [24].

Reports describing haemodynamic effects do not present consistent results. Shorten et al. in haemodynamic observations during induction of anaesthesia and intubation, showed that in the group of elderly people, but not receiving beta adrenolytics, there were no significant differences in the use of vecuronium at a dose of $0.12 \mathrm{mg} / \mathrm{kg}$ and rocuronium $0.9 \mathrm{mg} / \mathrm{kg}$. The authors concluded that rocuronium did not induce clinically significant changes in the form of HR, BP and serum catecholamine levels. Serum norepinephrine and adrenaline concentration increased at 1 minute after neuromuscular blocking agent administration and then normalized at $1 \mathrm{~min}$ after intubation to values similar to those before the start of anaesthesia 589-602-597 pg/ml for norepinephrine, and 444-520-440 pg/ml for adrenaline, respectively) [25].

Stevens et al. described that the use of rocuronium in a dose of $1.2 \mathrm{mg} / \mathrm{kg}$, as well as pancuronium in a dose of $0.1 \mathrm{mg} / \mathrm{kg}$ before intubation in ASA 1 and 2 patients, resulted in a significant increase in the heart rate compared to the state before this anaesthesiologic manoeuvres. The authors also observed a significant increase in MAP for rocuronium and pancuronium in relation to vecuronium [26]. Mathew et al. in the observation of the use of rocuronium in a dose of $0.6 \mathrm{mg} / \mathrm{kg}$, reported a significant increase in heart rate at 1 minute by $10 \%$, and at 5 minutes after the administration of the muscle relaxant by $14 \%$ compared to the value before anaesthesia, which was normalized after $10 \mathrm{~min}$ of observation. In addition, the authors noted a decrease in MAP values at 1 min after agent administration
[18]. Similar results were presented by Hyung Youn Kong et al. in haemodynamic parameters for patients with diabetes [27]. Also regarding the use of muscle relaxants as part of the treatment of critically ill patients requiring mechanical ventilation, a significant increase (4\%) in the heart rate was observed at $5 \mathrm{~min}$ after rocuronium administration in a dose of $0.6 \mathrm{mg} / \mathrm{kg}$ [28].

A special aspect of general anaesthesia is haemodynamic stabilization in the group of patients with significant cardiological disorders and undergoing cardiac surgery. In these situations, the pharmacological selection of anaesthetics, opioid drugs and a neuromuscular blocking agent is a crucial point. Many studies emphasized that the use of depolarizing agents - chlorosuccinylocholine should not be used routinely due to the potential risk of arrhythmia and bradycardia $[5,19,29,30]$. Virmani et al. comparing the effect of rocuronium in a dose of $0.6 \mathrm{mg} / \mathrm{kg}$, pancuronium $(0.1 \mathrm{mg} / \mathrm{kg})$ and vecuronium in a dose of $0.1 \mathrm{mg} / \mathrm{kg}$ in the group of patients undergoing valvular heart surgery, reported that at 5th minute after its administration there was a significant reduction in heart rate (93-82 beats/minute), and the values normalized 5 minutes after the intubation. Additionally, a significant reduction in the MAP and SAP values were noted. The authors suggested that rocuronium should be used for patients with a higher baseline heart rate [29]. Hudson et al. conducting invasive haemodynamic monitoring using a Swann-Ganz catheter during anaesthesia of patients in serious condition - ASA 3 and ASA 4 for cardiac surgery showed that the use of an intubation dose of rocuronium in dose $0.6 \mathrm{mg} / \mathrm{kg}$ and subsequent repeated doses of $0.2 \mathrm{mg} / \mathrm{kg}$ according to the relaxation monitoring did not cause clinically significant changes in the values of heart rate, mean arterial pressure, pulmonary capillary wedge pressure, cardiac index, stroke volume, systemic vascular resistance, and pulmonary vascular resistance. In addition, the authors noted a significant reduction in central venous pressurevalues at 2 and 5 minutes, and mean pulmonary artery pressure at 5 minutes after rocuronium administration. The authors stated that the changes in central venous pressure values and mean pulmonary artery pressure resulted from the dilatation of systemic venous vessels [32]. Ozturk et al. showed that the effects of a high dose of rocuronium (1.2 $\mathrm{mg} / \mathrm{kg})$ and a conventional - dose of rocuronium $(0.6 \mathrm{mg} / \mathrm{kg})$ in patients undergoing coronary artery revascularization/induction of anaesthe- 
sia on QTC were similar. The authors presented that the greatest prolongation occurred 2 min after intubation and returned to baseline 5 min after intubation. In both groups, the value of heart rate significantly decreased after rocuronium administration, but without negative clinical effects [33].

The present study aimed to investigate cardiac effects of rocuronium under combined general anaesthesia (sevoflurane and fentanyl). The authors evaluated the values of heart rate, systolic, diastolic, mean blood pressure in the maintenance phase of anaesthesia after exposure to intubation dose and continuous infusion of rocuronium. The authors demonstrated that the values of recorded parameters before and after anaesthesia were similar in both groups and did not differ significantly, and presented methods were safe for patients.

The results of this study complement the current knowledge on the subject of haemodynamic stability connected with neuromuscular blocking agents. By carrying out the study according to the presented methodology, it was possible to evaluate the influence of rocuronium on the haemodynamic status over a longer period than only the induction of anaesthesia and intubation. This observation concerned the circulatory parameters during all stages of general anaesthesia, and special observations were also made during the rocuronium infusion in the maintenance phase of anaesthesia. The main limitations of this study are the relatively small number of patients with a general good health condition (ASA 1 and ASA 2) and the use of one muscle relaxant. Researching according to the proprietary scheme in another study group construction, especially with ASA 3 and ASA 4 patients, would be a source of interesting results in the research topic. Of course, to describe the exact effect of the neuromuscular blocking agents on the haemodynamic stability, this scheme of study should be performed with other substances.

\section{CONCLUSION}

No vagolytic effect was observed during combined general anaesthesia with rocuronium using as an intubation dose, followed by continuous infusion to the level of deep surgical relaxation of skeletal muscles. There were significant changes in heart rate and blood pressure associated with the rocuronium infusion, which were normalized after the end of anaesthesia.

\section{REFERENCES}

1. Stäuble CG, Blobner M. The future of neuromuscular blocking agents. Curr Opin Anaesthesiol. 2020; 33(4): 490-498, doi: 10.1097/ AC0.0000000000000891, indexed in Pubmed: 32628397.

2. Smetana KS, Roe NA, Doepker BA, et al. Review of Continuous Infusion Neuromuscular Blocking Agents in the Adult Intensive Care Unit. Crit Care Nurs Q. 2017; 40(4): 323-343, doi: 10.1097/ CNQ.0000000000000171, indexed in Pubmed: 28834856.

3. Murphy GS. Neuromuscular Monitoring in the Perioperative Period. Anesth Analg. 2018; 126(2): 464-468, doi: 10.1213/ ANE.0000000000002387, indexed in Pubmed: 28795964.

4. Shantsila A, Gupta D, Lip GYH. Heart rate variability changes following catheter ablation for atrial fibrillation. Kardiol Pol. 2020; 78(3): 179-180, doi: 10.33963/KP.15249, indexed in Pubmed: 32218387.

5. Gunter A, Ruskin KJ. Intraoperative neurophysiologic monitoring: utility and anesthetic implications. Curr Opin Anaesthesiol. 2016; 29(5): 539-543, doi: 10.1097/AC0.0000000000000374, indexed in Pubmed: 27380045.

6. Schepens T, Cammu U. Neuromuscular blocade: what was, is and will be. Acta Anaesthesiol Belg. 2014; 4: 151-159.

7. Blobner M, Frick CG, Stäuble RB, et al. Neuromuscular blockade improves surgical conditions (NISCO). Surg Endosc. 2015; 29(3): 627-636, doi: 10.1007/s00464-014-3711-7, indexed in Pubmed: 25125097.

8. Bartels K, Esper SA, Thiele RH. Blood Pressure Monitoring for the Anesthesiologist: A Practical Review. Anesth Analg. 2016; 122(6): 1866-1879, doi: 10.1213/ANE.0000000000001340, indexed in Pubmed: 27195632.

9. Maheshwari K, Khanna S, Bajracharya G, et al. A Randomized Trial of Continuous Noninvasive Blood Pressure Monitoring During Noncardiac Surgery. Anesthesia \& Analgesia. 2018; 127(2): 424-431, doi: 10.1213/ane.0000000000003482.

10. Sokół-Kobielska E. Od kurary do esmeronu - czy to przepaść, czy tylko różnica? Anaesthesiol Intensive Ther. 2005; 2: 130-136.

11. Kristensen SD, Knuuti J, Saraste A, et al. [2014 ESC/ESA Guidelines on non-cardiac surgery: cardiovascular assessment andmanagement]. Kardiol Pol. 2014; 72(11): 857-918, doi: 10.5603/KP.2014.0193, indexed in Pubmed: 25524159.

12. Krzych $\measuredangle$, Kucewicz-Czech $E$. It is time for enhanced recovery after surgery in cardiac surgery. Kardiologia Polska. 2017; 75(5): 415-420, doi: 10.5603/kp.a2017.0014.

13. Gaszynski TM, Szewczyk T. Rocuronium for rapid sequence induction in morbidly obese patients: a prospective study for evaluation of intubation conditions after administration $1.2 \mathrm{mg} \mathrm{kg}{ }^{1}$ ideal body weight of rocuronium. Eur J Anaesthesiol. 2011; 28(8): 609-610, doi: 10.1097/EJA.0b013e32834753d0, indexed in Pubmed: 21562423.

14. Turan A, Chang C, Cohen B, et al. Incidence, Severity, and Detection of Blood Pressure Perturbations after Abdominal Surgery: A Prospective Blinded Observational Study. Anesthesiology. 2019; 130(4): 550-559, doi: 10.1097/ALN.0000000000002626, indexed in Pubmed: 30875354. 
15. Pendeville PE, Lois F, Scholtes JL. A comparison of intubation conditions and time-course of action with rocuronium and mivacurium for day case anaesthesia. Eur J Anaesthesiol. 2007; 24(6): 546-550, doi: 10.1017/S0265021506002341, indexed in Pubmed: 17241507.

16. Hemmerling TM, Russo G, Bracco D. Neuromuscular blockade in cardiac surgery: an update for clinicians. Ann Card Anaesth. 2008; 11(2): 80-90, doi: 10.4103/0971-9784.41575, indexed in Pubmed: 18603747.

17. Virmani $S$, Tempe DK, Datt $V$, et al. Effect of muscle relaxants on heart rate, arterial pressure, intubation conditions and onset of neuromuscular block in patients undergoing valve surgery. Ann Card Anaesth. 2006; 9(1): 37-43, indexed in Pubmed: 17699906.

18. Öztürk T, Ağdanli D, Bayturan 0̈, et al. Effects of conventional vs high-dose rocuronium on the QTC interval during anesthesia induction and intubation in patients undergoing coronary artery surgery: a randomized, double-blind, parallel trial. Braz J Med Biol Res. 2015; 48(4): 370-376, doi: 10.1590/1414-431X20144294, indexed in Pubmed: 25714880.

19. Gursoy S, Bagcivan I, Durmus N, et al. Investigation of the cardiac effects of pancuronium, rocuronium, vecuronium, and mivacurium on the isolated rat atrium. Curr Ther Res Clin Exp. 2011; 72(5): 195-203, doi: 10.1016/j.curtheres.2011.09.001, indexed in Pubmed: 24653506.

20. Castillo-Zamora C, Lespron Md, Nava-Ocampo AA. Similar preoperative hemodynamic response to pancuronium and rocuronium in high-risk cardiac surgical patients. Minerva Anestesiol. 2005; 71(12): 769-773, indexed in Pubmed: 16288184.

21. Bowman WC. Neuromuscular block. Br J Pharmacol. 2006; 147 Suppl 1: S277-S286, doi: 10.1038/sj.bjp.0706404, indexed in Pubmed: 16402115.

22. Mathew A, Sharma ANG, Ganapathi $P$, et al. Intraoperative hemodynamics with vecuronium bromide and rocuronium for maintenance under general anesthesia. Anesth Essays Res. 2016; 10(1): 59-64, doi: 10.4103/0259-1162.164740, indexed in Pubmed: 26957692.

23. Somani M, vyas S, Sharma P, et al. A Comparitive Study between Vecuronium and Rocuronium for Intubating Condition and Hemodynamic Changes. IOSR Journal of Dental and Medical Sciences. 2014; 13(6): 33-39, doi: 10.9790/0853-13613339.
24. P A. A Comparative Study of Rocuronium and Succinylcholine for Rapid Sequence Induction of Anaesthesia. Journal of Medical Science And clinical Research. 2016; 04(10): 13317-13324, doi: 10.18535/ jmscr/v4i10.85.

25. Kumar A, Saran J, Chandra R, et al. A COMPARATIVE CLINICAL EVALUATION OF INTUBATING CONDITIONS AND HAEMODYNAMIC EFFECTS AFTER ADMINISTRATION OF SUCCINYL CHOLINE \& ROCURONIUM BROMIDE. Journal of Evolution of Medical and Dental Sciences. 2015; 4(28): 4769-4780, doi: 10.14260/jemds/2015/693.

26. Wierda JM, Schuringa $M$, van den Broek L. Cardiovascular effects of an intubating dose of rocuronium $0.6 \mathrm{mg} \mathrm{kg}-1$ in anaesthetized patients, paralysed with vecuronium. Br J Anaesth. 1997; 78(5): 586-587, doi: 10.1093/bja/78.5.586, indexed in Pubmed: 9175978.

27. Belekar VB, Khamankar S. Rocuronium for tracheal intubation in patients undergoing emergency surgery. Int J Pharmacol Res. 2013; 3: $18-22$.

28. Parasa M, Vemuri NN, Shaik MS. Comparison of equipotent doses of rocuronium and vecuronium. Anesth Essays Res. 2015; 9(1): 88-91, doi: 10.4103/0259-1162.150676, indexed in Pubmed: 25886427.

29. Hudson ME, Rothfield KP, Tullock WC, et al. Haemodynamic effects of rocuronium bromide in adult cardiac surgical patients. Can J Anaesth. 1998; 45(2): 139-143, doi: 10.1007/BF03013252, indexed in Pubmed: 9512848.

30. Lee $S$, Lee J, Lee $S$, et al. The Effect of Nicorandil on the Pharmacodynamics of Rocuronium. Korean Journal of Anesthesiology. 2006; 50(5): 567, doi: 10.4097/kjae.2006.50.5.567.

31. Schramm WM, Strasser K, Bartunek A, et al. Effects of rocuronium and vecuronium on intracranial pressure, mean arterial pressure and heart rate in neurosurgical patients. Br J Anaesth. 1996; 77(5): 607-611, doi: 10.1093/bja/77.5.607, indexed in Pubmed: 8957976.

32. Shorten GD, Uppington J, Comunale ME. Changes in plasma catecholamine concentrations and haemodynamic effects of rocuronium and vecuronium in elderly patients. Eur J Anaesthesiol. 1998; 15(3): 335-341, doi: 10.1046/j.1365-2346.1998.00302.x, indexed in Pubmed: 9649995.

33. Stevens JB, Hecker RB, Talbot JC, et al. The haemodynamic effects of rocuronium and vecuronium are different under balanced anaesthesia. Acta Anaesthesiol Scand. 1997; 41(4): 502-505, doi: 10.1111/j.13996576.1997.tb04731.x, indexed in Pubmed: 9150779. 